\title{
Daughter-to-Father Attachment Style and Emerging Adult Daughter's Psychological Well-Being: Mediating Role of Interpersonal Communication Motives
}

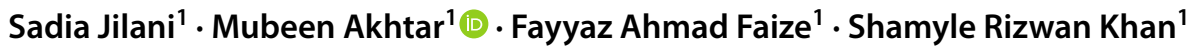 \\ Accepted: 14 November 2021 / Published online: 28 January 2022 \\ (c) The Author(s), under exclusive licence to Springer Science+Business Media, LLC, part of Springer Nature 2021
}

\begin{abstract}
This study investigated insecure attachment of emerging adult daughters with their fathers and how it affects daughter's psychological well-being, with interpersonal communication motives taken as mediating variables. A sample of daughters $(N=243)$ ranging from 18 to 25 years was collected through purposive sampling from Islamabad and Rawalpindi. For this cross-sectional study, data were collected using psychometrically sound tools along with a demographic data sheet. Results revealed that anxiety and avoidance attachment style negatively correlate to young adult daughters' psychological wellbeing as hypothesized. Moreover, this relationship is partially mediated by interpersonal communication motives. Among communication motives, affection motive is a stronger predictor of psychological well-being scores $(\beta=.31, p<.01)$. Other motives, i.e., pleasure, relaxation, inclusion, escape, and control did not show significant results in mediation. These findings have practical implications for parents, mental health professionals, and family counselors.
\end{abstract}

Keywords Insecure attachment $\cdot$ Psychological well-being $\cdot$ Communication motives $\cdot$ Daughter-father relationship

\section{Introduction}

Pakistan is a patriarchal society where women are expected to do household chores while men are the main source of income for the family. This demarcation in gender roles restricts fathers' time and interaction with their children after returning home. However, some recent studies have reported diversity and flexibility in fathers' role in caring for young children in the rural part of the country, suggesting more collaborative parenting (Bhamani, 2012; Jeong et al., 2018). Nevertheless, there is a dearth of literature concerning fathers' involvement in the parenting and upbringing of children. Moreover, within the indigenous perspective, research has yet to explore the unique bond that father and daughter constitute, affecting the lives of both in one way or the other. Zia et al. (2015) documented that father and daughter relationship quality significantly impacts daughter's self-esteem

Mubeen Akhtar

mubeen.akhtar@comsats.edu.pk

1 Department of Humanities, COMSATS University Islamabad (CUI), Park Road, Tarlai Kalan, Islamabad, Pakistan and academic achievement in a sample of adolescent girls. It is essential to study the father-daughter dyad since there are many phases of a daughter's life where a father generally has more influence than a mother, e.g., the father has a prominent effect on the capacity of the daughter to trust, appreciate, and relate well to the men in her life (Casiano, 2010; Erickson, 1998). It is imperative to mention that Pakistan is largely a Muslim society where only heterosexual romantic relationships are supported and accepted. A woman's fear of intimacy is greatly affected by the role her father played in her life. The level of fatherly approval affects the sexuality of his daughter and her propensity to become intimate with other people later in life (Scheffler \& Naus, 1999).

Culture influences the roles that individuals play in their day-to-day life and hence their relationships as well. Cultures are primarily identified as either individualistic or collectivistic; however, these two are not the opposite ends of the same construct. Instead, they are independent dimensions within a cultural context and are defined by the culture's primary goal or value orientation (Niles, 1998). With this understanding, collectivist cultures, such as predominantly in Pakistan, have the goal orientation of maintaining an emphasis on interpersonal relationships, caring, respecting, and serving elders, family, and others within the community. 
In comparison, individualistic cultures emphasize personal happiness, wealth, and profession more than the value of interpersonal relationships. It is not that the collectivist culture does not value personal happiness; instead, it derives personal happiness primarily through interpersonal goals (Niles, 1998). Parenting approach and role are also factors influenced by the cultural goal orientation which the family unit adheres to (Kotchick \& Forehand, 2002). The nature of each parent's role in the upbringing and life of their child essentially impacts the parent-child attachment.

The dual primary attachment model proposed by Bowlby (1982) adds insights regarding the roles of both mother and father as primary attachment figures, as opposed to the notion that mother alone is the primary attachment figure, and attachment with father may be secondary owing to its secondary role and significance (Newland \& Coyl, 2010). This model holds the premise that a father's attachment cannot be assumed as secondary since he shares the role of a parent, indicating that a sensitive and appropriate involvement of a father would positively influence the child's development, and his absence would harm the child's emotional development. Both parents hold a different nature of attachment with the child and influence the child differently, though equally significantly. Attachment with the mother provides a secure foundation to which the child can be confident to retreat at any instance, and the father plays the role of a trusted companion in fulfilling the child's exciting need to explore the world and oneself (Newland \& Coyl, 2010). In this dynamic, father and mother collectively provide a balanced context of secure exploration to the child, whereby they may develop autonomy, mastery, and other aspects of their well-being in the world by achieving tasks and forming fulfilling secondary attachments in relationships with other individuals (Bowlby, 1982).

By contrast, insecure attachment style can also be experienced by the individual towards the attachment figure. Bartholomew and Shaver (1998) proposed two dimensions of attachment, i.e., (i) anxious and (ii) avoidant. 'Anxious' is characterized by an absence of security in the attachment with significant others, worry about the relationship, need to be associated with the attachment figure, and fear of rejection. 'Avoidant' is defined as the absence of security concerning the emotional bonds; there is an inclination to distance from other people. Inflated or obsessive self-confidence is witnessed in this type of dimension. A secure attachment style ensures an experience of low anxiety and avoidance in the relationship with the attachment figure (Bartholomew \& Shaver, 1998). Individuals with secure attachment style are considerably better in psychosocial functioning than individuals with an anxious-preoccupied attachment style or fearful avoidant or dismissing-avoidant attachment (Greenberg, 2014). In addition, individuals reporting secure attachment styles are identified as less emotionally distressed than individuals with insecure attachment styles (Leerkes \& Siepak, 2006).

Research has shown that communication patterns play a significant role in attachment and relationship satisfaction (Punyanunt-Carter, 2008). Communication between parents and children contributes significantly to create effective relationships, understanding and mutual acceptance (Runcan et al., 2012). Communication is one of the key element in a daughter-father relationship and the quality of this relationship (Byrd-Craven et al., 2012). Communication motives explain what, how, and why people communicate with each other (Graham et al., 1993). Rubin et al. (1988) identified six distinct dimensions of communication motives: namely pleasure, affection, inclusion, escape, relaxation, and control. Buerkel-Rothfuss et al. (1995) noted that fathers communicated differently with their sons and daughters. Past research documented that communication motives have a significant impact on the perception of relationship satisfaction which is further linked with the psychological well-being of an individual (Punyanunt-Carter, 2005). In addition, the daughter's perceived level of communication and relational satisfaction with the father mediates between her interpersonal communication motives and psychological well-being (Heeman, 2008). Although the interpersonal communication motives are driven by sustaining attachments and fulfilling primary needs to ensure well-being, there is a dearth of empirical studies connecting the three factors in a single dynamic (Miller-Day 2004, 2005; Vazsonyi et al., 2003). This study addresses the mentioned gaps by exploring the mediating effect of interpersonal communication motives in daughter-father attachment and the psychological well-being of emerging adult daughters.

Psychological well-being is viewed as a one-dimensional construct in the present study. It is the degree to which one identifies one's purpose and meaning in life, has warm and fulfilling relationships, an optimistic view of self, engagement in life activities, contribution to others, competence, optimism, and self-esteem. This view of psychological well-being is based on the eudaimonic idea of well-being first conceptualized by Aristotle. It suggests that a state of well-being is a balance between identifying personal talents and goals, pursuing them through fulfilling actions, and maintaining external prosperity in meaningful interpersonal relationships and social goals (Ryff \& Singer, 2006). This idea ties with the secure primary attachment proposed by Bowlby, where a well-nurtured attachment with both parents brings about the balance of engaging in personal pleasures in the comfort of secure essential attachment (mother) and exploring new relationships and exciting social pursuits in the company of reliable companion (father) who will rescue them if need be. Secure primary attachments then optimize the chances of well-being in two distinct domains of functioning (Bowlby, 1969; Newland \& Coyl, 2010). Moreover, 
primary attachments initiate a pattern for later attachment style the person is likely to follow as emerging adult (Arnett, 2000, 2006; Miller-Day, 2008; Padilla-Walker et al., 2008). Emerging adult women who are in a transition period between late adolescence and young adulthood are studied as being less prone to developing psychological and emotional concerns if they have maintained a close relationship with their fathers, as compared to their counterparts with absent or insecure attachment with their father (Amato \& Dorius, 2010; Carlson, 2006; King \& Sobolewski, 2006).

Newland and Coyl (2010) identified that this model is based mainly on exploring attachment in the Western culture. Liu (2008) suggested studying model accuracy about the primary position of both mother and father attachments in collectivist cultures. Research in the recent past in the collectivist cultural context in Pakistan appears to confirm the primary influence of fathers' attachment on various aspects of relationship satisfaction and personal well-being (Jeong et al., 2018; Zia \& Shahzad, 2019). Another study reported an inverse relationship between positive father-daughter attachment and a daughter's interpersonal problems (Zia, \& Ali, 2014). However, the evidence is not sufficient to hold as established knowledge and require further exploration.

Figure 1 shows the conceptual framework of the current study. Attachment style (independent variable) in our model consists of two dimensions, (i.e., attachment-related anxiety and attachment-related avoidance). Those scoring low on both dimensions constitute secure attachment with significant other, and those scoring high on both dimensions constitute insecure attachment. Psychological well-being is the dependent variable in our study. Interpersonal communication motives, (i.e., pleasure, affection, inclusion, relaxation, escape, control), are mediators in our model mediating between attachment style and psychological well-being. "Path c" is the direct effect of an independent variable on the dependent variable, whereas "path a" and "b" both constitute indirect effects (mediation) in the model.

\section{The Rationale of the Study}

Collectivistic culture regulates the dynamics and frequency of communication with the fathers. In a collectivistic culture, every important life decision, including choosing a major, pursuing a career, or selecting a life partner, is made with parents' consent, particularly fathers. Moreover, being primarily a patriarchal society, daughters see their fathers as role models and look for their constant support and guidance, making them communicate regularly with their fathers. Moreover, the anxiety is generated by COVID-19 and the loss of friendship circle due to restricted movement (Faize \& Husain, 2021), and social support within one's family is also direly needed. This research is aimed to explore the communication motives that drive conversation between daughters and fathers in a collectivistic culture and whether these motives serve as mediators in the relationship between daughter-father attachment and daughters' psychological well-being. Some studies show signified attachment with fathers on regulating daughters' emotions in later adulthood (Pearce, 2009) and romantic partners (Bartholomew \& Shaver, 1998). However, the research literature is scarce regarding the significance of daughter-father insecure attachment on daughters' psychological well-being in emerging adulthood within the indigenous perspective. Therefore, this study may help explore young adult daughter-father interaction and its role in the daughter's psychological well-being.

The findings of this study may be helpful for parents, mental health professionals, and family counselors by providing insights into the daughters' psychological well-being. In addition, it will have significant implications on daughters' married life and day-to-day living since fathers are the role models for their daughters, and the way daughters interact with their fathers would, in one way or the other and impact the relationship with her spouse. Based on the findings from the past research, it was hypothesized that daughter-father
Fig. 1 Conceptual model of the study

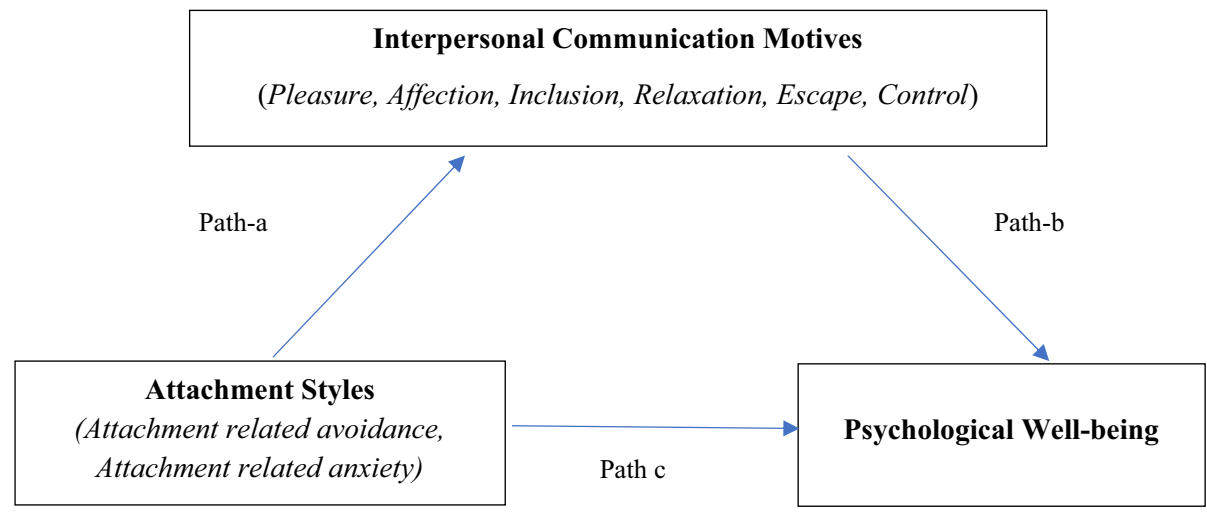

Note: Low attachment related avoidance and low attachment related anxiety correspond to secure attachment style and vice versa for insecure attachment style 
insecure attachment styles (attachment-related avoidance and attachment-related anxiety) are negatively correlated with the psychological well-being of emerging adult daughters in collectivistic patriarchal Muslim culture. Moreover, the relationship between daughter-father insecure attachment and the psychological well-being of emerging adult daughters is mediated by interpersonal communication motives within collectivistic patriarchal Muslim culture.

\section{Method}

\section{Research Design}

This study used a correlational survey research design to understand and evaluate the relationship between insecure daughter-father attachment styles and the psychological well-being of emerging adult daughters. In addition, the study also explored the mediating role of interpersonal communication motives on the daughters' psychological well-being.

\section{Sample}

The sampling technique employed was purposive sampling. The sample included 243 emerging adult daughters. The inclusion criteria were all the daughters having both parents alive and between the ages of 18 and 25 (emerging adulthood). Also, all of them were single and had varying educational qualifications, including intermediate, undergraduate, and graduate education.

The participants fall in the age range of 18-25 years with a mean value of $M=20.94$ ( $S D$ 1.88), and the majority were undergraduates $(n=170,70 \%)$. Concerning the birth order, $33.7 \%$ were firstborn, $46.5 \%$ were middle born, and $19.8 \%$ were lastborn. Furthermore, $64.6 \%$ of the daughters have both male and female gender siblings, $17.3 \%$ of daughters had only brothers as their siblings, whereas $18.1 \%$ of the total sample have only sisters. The majority of the daughters lived with their fathers $(81.5 \%)$. In comparison, $18.5 \%$ of the daughter's fathers resided in another town or city for work. Moreover, $74.1 \%$ of the daughters reported talking daily to their fathers, whereas $7.4 \%$ of daughters talked more than ten times per month, and $18.5 \%$ talked less than ten to their fathers during the last month.

\section{Measures}

\section{Interpersonal Communication Motives (ICM) Scale}

ICM is a 28 -item scale developed by Rubin et al. (1988). It is used to measure young adult daughters' communication motives for talking with their fathers. Motives of communication are assessed on six dimensions which include pleasure (8 items), affection (5 items), inclusion (4 items), escape (4 items), relaxation (4 items), and control (3 items). The 'pleasure' motive includes items like talking to others because they are exciting, stimulating, and enjoy social benefits. Affection motive point to one's need or want to offer help, tell others that one thinks about them, pay respects to other people, and show inspiration and concern. The motive of inclusion signifies the desire to be with others, talk to others, diminish loneliness, and gain reassurance, etc. The motive of escape is to express a need to procrastinate, fend off boredom, etc. Relaxation includes feeling more settled, lessen stress and tension, and feel the need to unwind oneself. Finally, control motive is about exerting power, getting someone's help, or gaining something important (Rubin et al., 1988).

The participants were asked the reason that make them communicate with their fathers. Items were rated based on how alike it was to their reason for talking to their fathers. Respondents rated themselves on a 5-point Likert scale ranging from 1 (not at all like my reasons) to 5 (exactly like my reasons). All the items in the subscales were summed separately and averaged. The reliability coefficients (Cronbach's alpha) for each of the six subscales reported in Rubin et al. (1988) are pleasure $(\alpha=.89)$, affection $(\alpha=.85)$, inclusion ( $\alpha=.84)$, escape $(\alpha=.77)$, relaxation $(\alpha=.81)$, and control $(\alpha=.75)$. In this study, the ICM subscales have good Cronbach's alpha reliability coefficients ranging from .77 (Control) to .92 (Pleasure). Iqbal (2013) also reported satisfactory reliability coefficients for ICM when used with a sample of young adults in Pakistan.

\section{Flourishing Scale (FS)}

Diener et al. (2009) developed the Flourishing Scale which was used to measure the psychological well-being of emerging adult daughters. It was previously known as the Psychological Well-being scale. This scale consists of 8 items: a self-report questionnaire measuring and focusing on individuals' self-perceived success in different areas of life, 
such as purpose and meaning in life, relationships, view of self, engagement in life activities, contribution to others, competence, optimism, and self-esteem. The scale provides a single psychological well-being score. Respondents rate themselves on each item on a 7-point Likert scale ranging from 1 (strongly disagree) to 7 (strongly agree). All the items are phrased in a positive direction. The responses on all the items are added to get a single score. The scores range from 8 (lowest possible psychological well-being) to 56 (highest possible psychological well-being). High scores indicate respondents' positive view of themselves in important areas of functioning. Items include, e.g., "I am competent and capable in the activities that are important to me." The scale has already been used with the indigenous population and is reported to have good psychometric properties (Ahmad et al., 2020; Khadim \& Shahid, 2017). The FS scale exhibited good reliability coefficient of .86 in the present study as well.

\section{The Relationship Structures Questionnaire (ECR-RS)}

Fraley et al. (2011) developed the Relationship Structures (ECR-RS) questionnaire to assess attachment styles in significant and in a variety of close relationships. The items were related to various interpersonal targets (not just focusing on romantic relationships) and various age groups. This instrument is a 9-item version of the 36-item "Experiences in Close Relationships Questionnaire-Revised (ECR-R)" (Fraley et al., 2000). Two scores, (i.e., attachment-related avoidance and attachment-related anxiety), are computed for fathers. Respondents rate each statement on a 7-point Likert scale with 1 (strongly disagree) to 7 (strongly agree). The avoidance score is computed by averaging items 1 to 6 ; items 1, 2, 3, and 4 are reverse scored. The anxiety score is computed by averaging items 7 to 9 . Items include "I usually talk about my problems and my concerns with this person," and "I am frequently concerned by the fact that this person does not care about me." Total score can be computed by adding score on all the items. The questionnaire has high reliability, with Cronbach's alpha .85 .

The range of scores for avoidance was 6 to 42, and for anxiety 3 to 21 . The scoring is compared to the ECR/RS dimensions. Those scoring low on avoidance and anxiety possess a secure attachment style. Conversely, those scoring high on avoidance and anxiety are labeled as insecure, namely fearful avoidant. This study used the dimensional model instead of the categorical model since individual experiences are subjective and breaking them into categories is ambiguous. The predictive validity of the ECR-R was supported by theoretically plausible associations between the attachment dimensions and assessments of both depressive symptoms and strategies of emotion regulation (e.g., Wei et al., 2005). The reliability coefficient of ECR-RS was .83 for attachment-related avoidance, .78 for attachmentrelated anxiety, and .81 for the total scale in this study. Malik and Björkqvist (2019) also reported satisfactory reliability for a sample of university teachers from Pakistan. The current study used the total insecure attachment scale scores for all analyses.

\section{Procedure}

The sample was taken from colleges and universities located in Islamabad and Rawalpindi. The departmental ethics review committee approved the study protocols. Informed consent was taken from participants after briefing them about the purpose and significance of the study. Participation in the research was voluntary. The participants were assured of the confidentiality of the information provided by them. All the research tools were in the English language, which took approximately 15 to $20 \mathrm{~min}$ to complete. Concerning the cultural suitability of the scales, an expert opinion was taken from the subject specialists $(n=3)$ involved in Psychology teaching and research at the university level. They were requested to read the statements of the assessment tools carefully and identify any culturally inappropriate items. The experts found all the items to be culturally relevant and suitable.

Moreover, a small pilot test $(N=15)$ was conducted to check the feasibility of measures, identify any languagerelated difficulty, culturally inappropriate word/item, understandability of instructions, and the average amount of time required to complete the survey. The data were collected through a survey method by using self-report measures. The participants were asked to fill the instruments in person and return them to the researcher. Based on the feedback, no change was made in the scales.

\section{Analysis Scheme}

The SPSS software (version 26) was used to analyze the data. The Pearson correlation and mediation analysis were computed to test study hypotheses. Analysis was carried out at a .05 level of significance.

\section{Results}

\section{Correlations Among Study Variables}

Table 1 demonstrates the correlations among study variables. Daughter-father insecure attachment has significant negative correlation with psychological well-being of emerging adult daughter $(r=-.41, p<.01)$ as hypothesized. Low scores on 
Table 1 Correlations between study variables $(N=243)$

\begin{tabular}{|c|c|c|c|c|c|c|c|c|c|c|}
\hline Variables & 1 & 2 & 3 & 4 & 5 & 6 & 7 & 8 & $M(S D)$ & $\alpha$ \\
\hline 1. Insecure attachment & - & $-.41 * *$ & $-.62 * *$ & $-.46^{* *}$ & $-.41 * *$ & $-.15^{*}$ & $-.64 * *$ & .005 & $25.73(10.16)$ & .81 \\
\hline 2. Well-being & - & - & $.37 * *$ & $.39 * *$ & $.20 * *$ & .04 & $.30 * *$ & .01 & $42.74(8.50)$ & .86 \\
\hline 3. Pleasure & - & - & - & $.58 * *$ & $.52 * *$ & $.30 * *$ & $.73 * *$ & -.02 & $28.47(7.50)$ & .92 \\
\hline 4. Affection & - & - & - & - & $.60 * *$ & $.34 * *$ & $.60 * *$ & $.25^{* *}$ & $18.40(4.55)$ & .86 \\
\hline 5. Inclusion & - & - & - & - & - & $.58 * *$ & $.70 * *$ & $.33 * *$ & $12.21(4.26)$ & .85 \\
\hline 6. Escape & - & - & - & - & - & - & $.43 * *$ & $.47 * *$ & $9.81(4.13)$ & .84 \\
\hline 7. Relaxation & - & - & - & - & - & - & - & $.15^{*}$ & $13.73(4.17)$ & .89 \\
\hline 8. Control & - & - & - & - & - & - & - & - & $8.51(3.12)$ & .77 \\
\hline
\end{tabular}

$* p<.05, * * p<.01$

the attachment scale (anxiety and avoidance dimensions) indicate a secure attachment style which is associated with a high score on psychological well-being. It was also found that daughter-father insecure attachment had significant negative associations with all interpersonal communication motives except for control which suggests that low score on the anxiety and avoidance dimensions for daughter-father attachment is linked with high scores on pleasure, affection, inclusion, and relaxation motives. Moreover, interpersonal communication motives of pleasure, affection, inclusion, and relaxation significantly correlated with psychological wellbeing in the positive direction.

\section{Mediation Analysis}

Multiple regression analyses were conducted to assess each component of the proposed mediation model and to test formulated hypotheses. Results are presented in Table 2 showing standardized and unstandardized regression coefficients (also see Fig. 2).

\section{Total Effect}

Results suggest that daughter-father insecure attachment is inversely associated with psychological well-being ( $\beta=-.38, t=-6.14(241), p=.000)$. Low scores on the attachment dimension (avoidance related and anxiety related) show a secure attachment, which predict a high score on psychological well-being of daughters.

\section{Direct Effects}

Significant direct effects were found between daughter-father attachment and communication motives. Results showed that low scores on daughter-father insecure attachment predict high scores on interpersonal communication motives including pleasure $(\beta=-.62, p=.000)$, affection $(\beta=-.46, p=.000)$, inclusion $(\beta=-.41, p=.000)$, escape $(\beta=-.15, p=.017)$, and relaxation $(\beta=-.64, p=.000)$, except for control which did not display significant results. This indicates that low scores on daughter-father insecure attachment (i.e., secure attachment) are associated with an increased likelihood to use pleasure, affection, inclusion, escape, and relaxation motives for communication.

Findings also showed that communication motives are significantly correlated with psychological well-being. Pleasure $(\beta=.21, p=.024)$ and affection motive $(\beta=.31$, $p=.000)$ significantly and positively predicted psychological well-being while other communication motives including inclusion, escape, relaxation, and control did not display significant results.

\section{Indirect Effect}

There was a significant indirect effect of daughter-father attachment on psychological well-being of emerging adult daughter through interpersonal communication motives. The motive of affection positively predicted well-being $(\beta=.28$, $p=.001)$ along with attachment $(\beta=-.19, p=.021)$. Approximately $22 \%$ variance in psychological well-being scores of daughters was accounted for by the predictors $\left(R^{2}=.216\right)$. Control motive together with other motives excluding affection, however, was not a significant predictor of psychological well-being.

\section{Testing Mediation Model with Bootstrapping}

Since both the a-path and b-path were significant, mediation analysis was tested using the bootstrapping method with bias-corrected coefficient estimates (MacKinnon et al., 2004; Preacher \& Hayes, 2004). In the present study, the $95 \%$ confidence interval of the indirect effects was obtained with 5000 bootstraps resamples (Preacher \& Hayes, 2008). Results of the mediation analysis confirmed the mediating role of interpersonal communication motive (i.e., affection) in the relationship between daughter-father attachment dimensions and psychological well-being of daughter. 
In addition, results indicated that the direct effect of insecure attachment on psychological well-being is reduced $(B=-.19, t(235)=2.33, p=.021)$ when controlling for interpersonal communication motives, thus, suggesting partial mediation. Model fit indices showed all communication motives, except affection, have CIs that include zero and, therefore, are not significant (see Table 3).

\section{Discussion}

The current study aimed to investigate the relationship between daughter to father style of attachment and emerging adult daughters' psychological well-being. In addition, the mediating role of communication motives was explored in the relationship between attachment style and psychological well-being. Data of the study supported the hypothesis that daughter-father insecure attachment (attachment-related avoidance and attachment-related anxiety) is negatively correlated with the psychological well-being of emerging adult daughters in a collectivistic patriarchal Muslim culture. Low scores on attachment represent a secure daughter-father attachment style which corresponds to a high score on psychological well-being of daughter.
The most prominent contribution of the present study is identifying the significant role of affection as an interpersonal communication motive mediating the relationship between an emerging adult daughter's attachment with her father and her psychological well-being. This shows that communication with the father in a secure attachment fulfills the daughter's primary need for affection (Rubin \& Martin, 1998), and her psychological well-being also increases. These findings corroborate the existing literature in individualistic cultures (Heeman, 2008; Katorski, 2003). Women communicate mostly to express affection, seek relaxation, pleasure, inclusion, and much less control (Liu, 1975; Rubin et al., 1988). Communication with a significant degree of affection motive also reveals that the daughters in the present study had the least communication apprehension and expressed themselves freely with father with least anxiety (Rubin \& Martin, 1998).

The order of motive reported in this study from most used to least used are (a) affection, (b) pleasure, (c) relaxation, (d) inclusion, (e) control, and (f) escape. Although, none of the other motives were significant in their impact on the dynamic of the daughter's paternal attachment and her psychological well-being in the present collectivistic culture. This contrasts with the finding in an individualistic culture,
Table 2 Standardized and unstandardized regression coefficients from mediation analysis

\begin{tabular}{lcccccc}
\hline Predictors & $\mathrm{B}$ & $\mathrm{SE}$ & $\beta$ & $\mathrm{t}$ & $\mathrm{p}$ & $\mathrm{R}^{2}$ \\
\hline $\mathrm{IA} \rightarrow \mathrm{PW}$ & -.31 & .05 & -.38 & -6.14 & .000 & .13 \\
$\mathrm{IA} \rightarrow \mathrm{ICM}$ & & & & & & \\
Pleasure & -.46 & .04 & -.62 & -12.23 & .000 & \\
Affection & -.21 & .03 & -.46 & -8.10 & .000 & \\
Inclusion & -.17 & .03 & -.41 & -6.87 & .000 & \\
Escape & -.06 & .03 & -.15 & -2.41 & .017 & \\
Relaxation & -.26 & .02 & -.64 & -12.98 & .000 & \\
Control & .001 & .02 & .003 & .04 & .961 & \\
ICM $\rightarrow$ PW & & & & & & \\
Pleasure & .24 & .11 & .21 & 2.28 & .024 & .19 \\
Affection & .57 & .15 & .31 & 3.75 & .000 & \\
Inclusion & -.15 & .18 & -.07 & -.81 & .416 & \\
Escape & -.25 & .15 & -.12 & -1.56 & .129 & \\
Relaxation & .16 & .21 & .08 & .75 & .450 & \\
Control & .03 & .19 & .01 & .13 & .896 & \\
IA + ICM $\rightarrow$ PW & & & & & & \\
Attachment & -.16 & .07 & -.19 & -2.33 & .021 & .23 \\
Pleasure & .18 & .11 & .16 & 1.69 & .091 & \\
Affection & .53 & .15 & .28 & 3.52 & .001 & \\
Inclusion & -.14 & .19 & -.07 & -.73 & .465 & \\
Escape & -.21 & .16 & -.10 & -1.27 & .207 & \\
Relaxation & -.02 & .22 & -.01 & -.09 & .931 & \\
Control & .04 & .18 & .01 & .19 & .844 & \\
\hline
\end{tabular}

$I A$ insecure attachment (anxiety and avoidance dimension), $P W$ Psychological well-being, ICM: interpersonal communication motives 


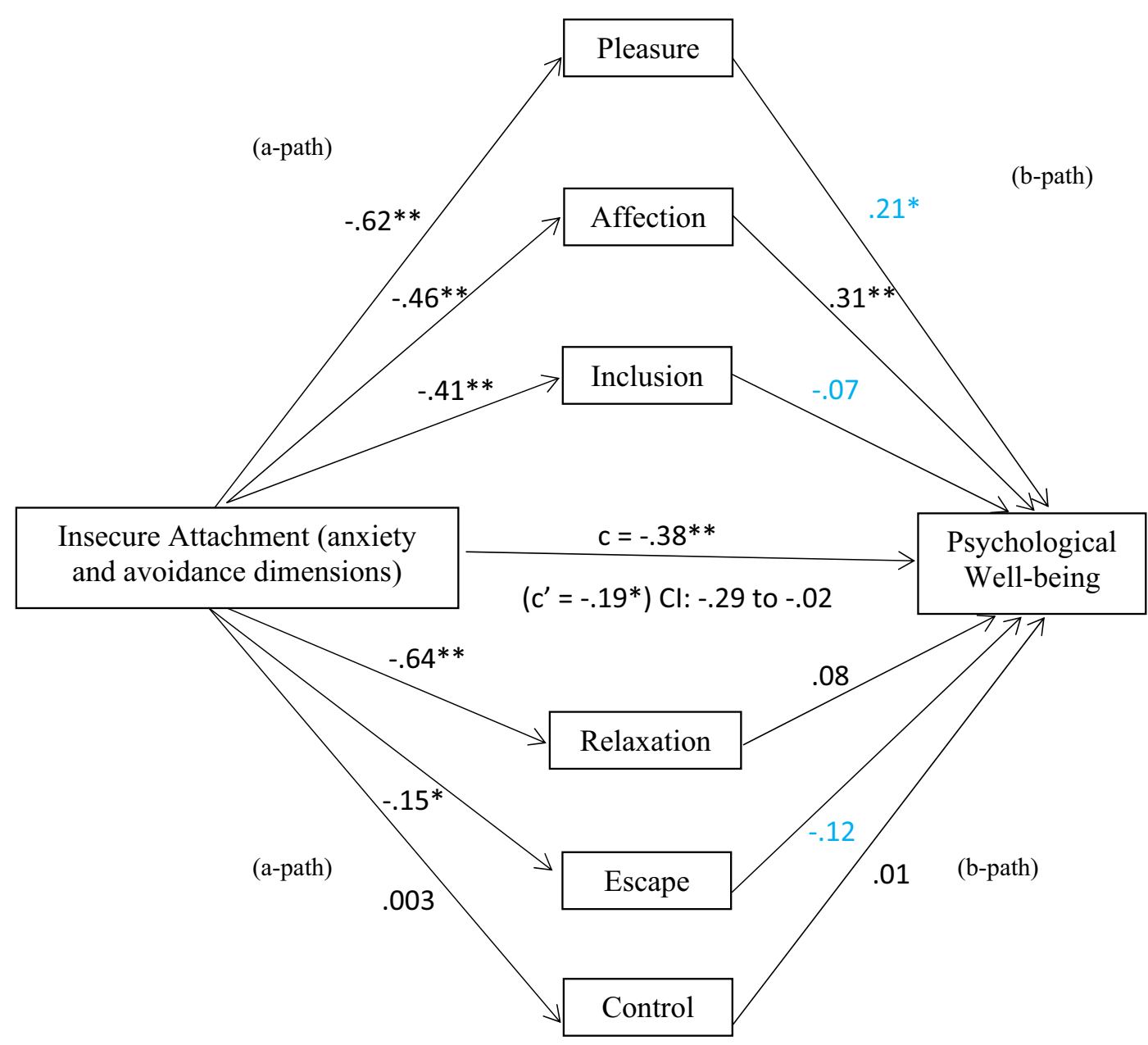

Note: After controlling for interpersonal communication motives, the standardized regression coefficient between insecure attachment dimensions and psychological well-being is in parenthesis.

$* p<.05, * * p<.01$

Fig. 2 The indirect effect of insecure attachment dimensions on psychological well-being through interpersonal communication motives

where Punyanunt-Carter (2007) found that the more secure a daughter's perceived attachment is with her father (individualist culture), the more she operates on the motive of escape as compared to their anxious/avoidant counterparts. While escape is the least reported motive, affection is the most reported motive for communication for the present collectivistic finding. The order of communication motives shows escape motives serve secondary order needs to reduce stress; affection motive indicates that the communication is aimed to fulfill a primary need of safety and security (Rubin \& Martin, 1998). This points to the goal orientation of collectivist cultures as gaining primary order personal well-being through a shared connection insecure attachment, while in an individualistic culture, the primary goals are individualfocused pursuits.
Punyanunt-Carter (2005) found that fathers and daughters share the communication motives of affection, pleasure, and relaxation and revealed that communication with these motives increased their relationship satisfaction (Rubin et al., 1988) which supports our findings in this study. One interesting result is that while affection is a primary order motive, both pleasure and relaxation are secondary order motives. This reinforces the validity of the dual primary attachment model in the collectivist culture, where the paternal attachment facilitates exploration and excitement-related pursuits by the child, relatively more than ensuring safety and security. Although further research is needed to establish this link, it is suggested that in the collectivist culture of Pakistan, daughters' relationships with fathers are significant 
Table 3 Testing mediation model through bootstrapping

\begin{tabular}{|c|c|c|c|c|c|c|}
\hline Effect & SE & $\mathrm{T}$ & & $\mathrm{p}$ & LLCI & ULCI \\
\hline \multicolumn{7}{|c|}{ Total effect of insecure attachment on well-being } \\
\hline-.3073 & .0501 & 6.1383 & & .0000 & -.4060 & -.2087 \\
\hline \multicolumn{7}{|c|}{ Direct effect of Insecure Attachment on Well-being } \\
\hline \multirow[t]{2}{*}{-.1559} & .0670 & 2.3283 & & .0207 & -.2878 & -.0240 \\
\hline & Effect & & BootSE & & BootLLCI & BootULCI \\
\hline \multicolumn{7}{|c|}{ Indirect effect(s) of attachment on well-being } \\
\hline Total & -.1514 & & .0537 & & -.2565 & -.0449 \\
\hline Pleasure & -.0823 & & .0509 & & -.1863 & .0181 \\
\hline Affection & -.1098 & & .0335 & & -.1766 & -.0461 \\
\hline Inclusion & .0232 & & .0289 & & -.0363 & .0802 \\
\hline Escape & .0125 & & .0105 & & -.0068 & .0350 \\
\hline Relaxation & .0050 & & .0615 & & -.1220 & .1230 \\
\hline Control & .0000 & & .0039 & & -.0075 & .0099 \\
\hline
\end{tabular}

primary attachments, where they seek to fulfill their primary needs from this attachment even as an emerging adult.

\section{Implications}

This study highlights the significance of father's active parental role in the primary relationship and attachment blueprints of their daughters. This is specifically noteworthy in the Pakistani culture, where the gender roles typically prescribe the mother as the primary caregiver, and the father is viewed only in a supportive capacity. This finding has implications in educating both parents on shared roles in their child-rearing approach. It also sheds light on the father's significance, making himself available for communication as his daughter grows into an adult and explores secondary attachments.

\section{Limitations and Suggestions for Future Research}

The sample in this study belonged to an urban demographic sub-culture of educated emerging adult women studying at the university level. This represents a smaller section of only $8.86 \%$ of the urban population having intermediate-level education (Pakistan Bureau of Statistics, 2021). Therefore, it may be that this sub-cultural goal orientation differs from the larger cultural goal orientation of the region, which is not represented in this study.

The study measured the perceived attachment style of daughters towards fathers for which data were collected only from daughters. This has left room for exploration into the shared dynamic between daughters and fathers in the collectivist culture from father's perspective. In addition, future research in this context could explore the influence of interpersonal communication motives with mothers on a daughter's psychological well-being compared to fathers.

\section{Conclusion}

The present study revealed that, among the interpersonal communication motives, affection motive mediated the relationship between attachment style and psychological well-being of emerging adult daughters. Securely attached daughters, who are low on anxiety and avoidance dimensions of attachment, would affectively talk with their fathers, showing care and concern. This would, in turn, positively impact their psychological well-being (Akhtar et al., 2019). She would feel accepted, have high self-esteem, and would be socially interactive. On the other hand, daughters with insecure attachment (high on both anxiety and avoidance dimension) would not talk with their fathers because of affection motive and will not express their feelings and concerns openly. Ultimately this would influence their psychological well-being negatively. Thus, active parental involvement from the father as a primary attachment figure would enable the daughter to fulfill her primary needs through this relationship and form healthier patterns of secondary attachment, contributing to her psychological well-being besides impacting other life areas.

Funding The research was not funded by any organization.

Data Availability Data can be made available when required.

Code Availability Not applicable. 


\section{Declarations}

Conflict of interest The authors declare that they have no conflict of interest.

Ethical Approval Ethical approval for the study was taken from ethic review committee of the institution where the research was carried out. All procedures performed in this study involving human participants were in accordance with the ethical standards of the institutional and/ or national research committee and with the 1964 Helsinki declaration and its later amendments or comparable ethical standards.

Consent to Participate Informed consent was obtained from all the individual participants included in the study.

Consent for Publication All the researchers agree to publish this work.

\section{References}

Ahmad, S., Nasreen, L., \& Aiman, M. (2020). Shyness and psychological well-being as predictors of problematic internet use among students in Pakistan. Psicología, Conocimiento y Sociedad, 10(3), 7-26. https://doi.org/10.26864/PCS.v10.n3.1

Akhtar, M., Kroener-Herwig, B., \& Faize, F. A. (2019). Depression and anxiety among international medical students in Germany: The predictive role of coping styles. Journal of the Pakistan Medical Association, 69(2), 230-234.

Amato, P., \& Dorius, C. (2010). Father, children and divorce. In M. Lamb (Ed.), Role of the father in child development. New York: Wiley.

Arnett, J. J. (2000). Emerging adulthood: A theory of development from the late teens through the twenties. American Psychologist, 55, 469-480. https://doi.org/10.1037/0003-066X.55.5.469

Arnett, J. J. (2006). The Psychology of emerging adulthood: What is known, and what remains to be known. In J. J. Arnett \& J. L. Tanner (Eds.), Emerging adults in America: Coming of age in the 21st century (pp. 303-330). American Psychological Association.

Bartholomew, K., \& Shaver, P. R. (1998a). Methods of assessing adult attachment. In J. A. Simpson \& W. S. Rholes (Eds.), Attachment theory and close relationships (pp. 25-45). The Guilford Press.

Bhamani, S. (2012). Urban fathers' involvement in early childhood development: A case study from Pakistan. Perspectives in Infant Mental Health, 20(3-4), 19.

Bowlby, J. (1969). Attachment and Loss: Attachment, 1. Penguin Books.

Bowlby, J. (1982). Attachment and loss: Retrospect and prospect. American Journal of Orthopsychiatry, 52(4), 664.

Buerkel-Rothfuss, N. L., Fink, D. S., \& Buerkel, R. A. (1995). Communication in father-child dyad. In T. S. Socha \& G. H. Stamp (Eds.), Parents, children, and communication: Frontiers of theory and research (pp. 63-86). Lawrence Erlbaum.

Byrd-Craven, J., Auer, B. J., Granger, D. A., \& Massey, A. R. (2012). The father-daughter dance: The relationship between fatherdaughter relationship quality and daughters' stress response. Journal of Family Psychology, 26(1), 87. https://doi.org/10.1037/ $\mathrm{a} 0026588$

Carlson, M. (2006). Family structure, father involvement and adolescent outcomes. Journal of Marriage and Family, 68, 137-154. https://doi.org/10.1111/j.1741-3737.2006.00239.x

Casiano, R. (2010). The influence of father-daughter relationship quality on current romantic relationship quality in women. The University of Oklahoma.
Diener, E., Wirtz, D., Tov, W., Kim-Prieto, C., Choi, D., Oishi, S., \& Biswas-Diener, R. (2009). New measures of well-being: Flourishing and positive and negative feelings. Social Indicators Research, 39, 247-266.

Erickson, B. (1998b). Longing for dad. Health Communications.

Faize, F. A., \& Husain, W. (2021). Students with severe anxiety during COVID-19 lockdown-exploring the impact and its management. The Journal of Mental Health Training, Education and Practice, 16(2), 153-163. https://doi.org/10.1108/JMHTEP-09-2020-0062

Fraley, R. C., Heffernan, M. E., Vicary, A. M., \& Brumbaugh, C. C. (2011). The experiences in close relationships-Relationship Structures Questionnaire: A method for assessing attachment orientations across relationships. Psychological Assessment, 23(3), 615-625. https://doi.org/10.1037/a0022898

Fraley, R. C., Waller, N. G., \& Brennan, K. A. (2000). An item response theory analysis of self-report measures of adult attachment. Journal of Personality and Social Psychology, 78(2), 350. https://doi.org/10.1037/0022-3514.78.2.350

Graham, E. E., Barbato, C. A., \& Perse, E. M. (1993). The interpersonal communication motives model. Communication Quarterly, 41(2), 172-186. https://doi.org/10.1080/01463379309369877

Greenberg, S. (2014). Attachment style, perceived life events, and psychological well-being in adults coping with bipolar disorder: A longitudinal study. Retrieved June 20, 2020, from https://etd. ohiolink.edu/

Heeman, V. C. (2008). Interpersonal communication motives, satisfaction, and psychological well-being in father-young adult daughter relationships (Doctoral dissertation, Kent State University).

Iqbal, Y. W. (2013). Usage of social networking sites: Interpersonal communication motives of youth. Journal of Media Studies, $28(2), 129-144$

Jeong, J., Siyal, S., Fink, G., McCoy, D. C., \& Yousafzai, A. K. (2018). "His mind will work better with both of us": A qualitative study on fathers' roles and coparenting of young children in rural Pakistan. BMC Public Health, 18(1), 1274. https://doi.org/10.1186/ s12889-018-6143-9

Katorski, J. (2003). Father/daughter relationships: Effects of communicative adaptability and satisfaction on daughter's romantic relationships. UWL Journal of Undergraduate Research, 6, 1-6.

King, V., \& Sobolewski, D. (2006). Nonresident fathers' contributions to adolescent well-being. Journal of Marriage and Family, 68, 537-557. https://doi.org/10.1111/j.1741-3737.2006.00274.x

Khadim, U. \& Shahid, A. (2017). Gratitude and Altruism as predictors of psychosocial well-being among adolescents. In MDSRC-2017 Proceedings, 27-28 December, 2017 Wah/Pakistan

Kotchick, B. A., \& Forehand, R. (2002). Putting parenting in perspective: A discussion of the contextual factors that shape parenting practices. Journal of Child and Family Studies, 11(3), 255-269. https://doi.org/10.1023/a:1016863921662

Leerkes, E. M., \& Siepak, K. J. (2006). Attachment linked predictors of women's emotional and cognitive responses to infant distress. Attachment \&amp; Human Development, 8(1), 11-32. https://doi. org/10.1080/14616730600594450

Liu, Y. (2008). An examination of three models of the relationships between parental attachments and adolescents' social functioning and depressive symptoms. Journal of Youth and Adolescence, 37, 941-952. https://doi.org/10.1007/s10964-006-9147-1

Liu, A. Y. (1975). Interpersonal relationships within an integrated setting. Psychological Reports, 36, 138. https://doi.org/10.2466/pr0. 1975.36.1.138

MacKinnon, D. P., Lockwood, C. M., \& Williams, J. (2004). Confidence limits for the indirect effect: Distribution of the product and resampling methods. Multivariate Behavioral Research, 39(1), 99-128. https://doi.org/10.1207/s15327906mbr3901_4 
Malik, N. A., \& Björkqvist, K. (2019). Workplace bullying and occupational stress among University Teachers: Mediating and moderating factors. Europe's Journal of Psychology, 15(2), 240-259. https://doi.org/10.5964/ejop.v15i2.1611

Miller-Day, M. A. (2004). Communication among grandmothers, mothers, and adult daughters: A qualitative study of maternal relationships. Earlbaum.

Miller-Day, M. A. (2005). Necessary convergence of meaning in interpersonal relationships. In Paper presented at the annual meeting of the International Communication Association, New York.

Miller-Day, M. (2008). Talking to youth about drugs: What do late adolescents say about parental strategies? Family Relations, 57, 1-12. https://doi.org/10.1111/j.1741-3729.2007.00478.x

Newland, L. A., \& Coyl, D. D. (2010). Fathers' role as attachment figures: An interview with Sir Richard Bowlby. Early Child Development and Care, 180(1-2), 25-32. https://doi.org/10.1080/03004 430903414679

Niles, F. S. (1998). Individualism-collectivism revisited. Cross-Cultural Research, 32(4), 315-341. https://doi.org/10.1177/10693 9719803200401

Padilla-Walker, L. M., Nelson, L. J., Madsen, S. D., \& Barry, C. M. (2008). The role of perceived parental knowledge on emerging adults' risk behaviors. Journal of Youth and Adolescence, 37(7), 847-859. https://doi.org/10.1007/s10964-007-9268-1

Pakistan Bureau of Statistics. (2021). Educated population by level of education. Retrieved February 13, 2021, from https://www.pbs. gov.pk/content/educated-population-level-education

Pearce, C. (2009). Daughter-to-Father Attachment, Daughter-to-Mother Attachment and Emotion Regulation in College Females (Doctoral dissertation)

Preacher, K. J., \& Hayes, A. F. (2004). SPSS and SAS procedures for estimating indirect effects in simple mediation models. Behavior Research Methods, Instruments, and Computers, 36, 717-731.

Preacher, K. J., \& Hayes, A. F. (2008). Asymptotic and resampling strategies for assessing and comparing indirect effects in multiple mediator models. Behavior Research Methods, 40(3), 879-891. https://doi.org/10.3758/BRM.40.3.879

Punyanunt-Carter, N. M. (2005). Father and daughter motives and satisfaction. Communication Research Reports, 22(4), 293-301. https://doi.org/10.1080/000368105000317573

Punyanunt-Carter, N. M. (2007). Using attachment theory to study communication motives in father-daughter relationships. Communication Research Reports, 24(4), 311-318. https://doi.org/10. 1080/08824090701624213

Punyanunt-Carter, N. M. (2008). Father-daughter relationships: Examining family communication patterns and interpersonal communication satisfaction. Communication Research Reports, 25(1), 23-33. https://doi.org/10.1080/08824090701831750

Rubin, R. B., \& Martin, M. M. (1998c). Interpersonal communication motives. In J. C. McCroskey \& J. A. Daly (Eds.), Communication and personality: Trait perspectives (pp. 287-307). Hampton Press.

Rubin, R. B., Perse, E. M., \& Barbato, C. A. (1988). Conceptualization and measurement of interpersonal communication motives. Human Communication Research, 14(4), 602-628. https://doi.org/ 10.1111/j.1468-2958.1988.tb00169.x

Runcan, P. L., Constantineanu, C., Ielics, B., \& Popa, D. (2012). The role of communication in the parent-child interaction. ProcediaSocial and Behavioral Sciences, 46, 904-908. https://doi.org/10. 1016/j.sbspro.2012.05.221

Ryff, C. D., \& Singer, B. H. (2006). Know thyself and become what you are: A eudaimonic approach to psychological well-being. Journal of Happiness Studies, 9(1), 13-39. https://doi.org/10. 1007/s10902-006-9019-0

Scheffler, T., \& Naus, P. (1999). The relationship between fatherly affirmation and a woman's self-esteem, fear of intimacy, comfort with womanhood and comfort with sexuality. Canadian Journal of Human Sexuality, 8, 39-45.

Vazsonyi, A. T., Hibbert, J. R., \& Snider, J. B. (2003). Exotic enterprise no more? Adolescent reports of family and parenting processes from youth in four countries. Journal of Research on Adolescence, 13(2), 129-160. https://doi.org/10.1111/1532-7795.1302001

Wei, M., Vogel, D. L., Ku, T. Y., \& Zakalik, R. A. (2005). Adult attachment, affect regulation, negative mood, and interpersonal problems: The mediating roles of emotional reactivity and emotional cutoff. Journal of Counseling Psychology, 52(1), 14-24. https:// doi.org/10.1037/0022-0167.52.1.14

Zia, A., \& Ali, S. M. (2014). Positive father and daughter relationship and its impact on daughter's interpersonal problem. Journal of Social Sciences and Humanities, 53(2), 61-68. https://doi.org/ 10.46568/jssh.v53i2.170

Zia, A., \& Shahzad, S. (2019). Depression and perceived attachment of adolescents with fathers having substance-abuse disorder. Journal of Pakistan Medical Association. https://doi.org/10.5455/jpma. 15016

Zia, A., Malik, A. A., \& Ali, S. M. (2015). Father and daughter relationship and its impact on daughter's self-esteem and academic achievement. Academic Journal of Interdisciplinary Studies, 4(1), 311. https://doi.org/10.5901/ajis.2015.v4n1p311

Publisher's Note Springer Nature remains neutral with regard to jurisdictional claims in published maps and institutional affiliations. 